\title{
Pitfalls in catheter-based interventions to treat paravalvular leaks
}

Andreas Bairaktaris, MD, Nikolaus A. Haas, MD, Dirk Seifert, MD, Rainer Schaeffler, MD, Heinrich Koertke, MD, Soren Schenk, MD, and Reiner Koerfer, MD, Bad Oeynhausen, Germany

Paravalvular leaks of prosthetic heart valves can be observed at a rate as great as $1.4 \%$ leaks/patient-year. ${ }^{1}$ Surgical correction can be performed with low mortality in most instances of clinically relevant regurgitation or hemolysis. ${ }^{2}$ More recently, interventional cardiologic techniques are of growing interest. This report depicts 3 patients who required surgical treatment for interventional complications. Current challenges and indications for this evolving technology are discussed.

\section{CLINICAL SUMMARIES}

PATIENT 1. A 73-year-old man was referred for grade III mitral regurgitation caused by a persistent paravalvular leak. The patient had undergone implantation of a bioprosthesis in the mitral position at 53 years of age. This prosthesis was replaced when the patient was 66 years old with a mechanical prosthesis because of valve degeneration. A relevant paravalvular leak was diagnosed 6 years after the last valve exchange and prompted 2 attempts at interventional closure with the Amplatzer PDA Occluder Device (AGA Medical Corporation, Golden Valley, Minn). The patient had increasing hemolysis, and his clinical status progressively declined within the subsequent 2 years. Fluoroscopy revealed mitral insufficiency caused by restriction of leaflet motion by an occluder device. Intraoperative findings confirmed the imaging studies (Figure 1). A third valve replacement and the subsequent postoperative course were uneventful.

PATIENT 2. The second patient was a 21-year-old woman with 3 previous operations for truncus arteriosus communis type 1 . Banding of the pulmonary artery at the age of 1 year was followed by an extracardiac conduit and ventricular septal defect closure 4 years later. Replacements of pulmonary and aortic valves with mechanical prostheses were necessary when the patient was 13 years old. Paravalvular leakage of the aortic valve was diagnosed at the age of 20 years and then treated by intervention with 2 Amplatzer PDA Occluder Devices (Figure 2). Although her aortic insufficiency was reduced to grade I, significant hemolysis developed. Six months later, the patient was referred for surgery for valve replacement. Intraoperatively, the 2 devices were found to be correctly placed to occlude 1 paravalvular leak, whereas another leak was present opposite to the first and not treated.

\footnotetext{
From the Department of Cardiovascular Surgery, Heart Center NRW, Bad Oeynhausen, Germany.

Received for publication Aug 14, 2007; accepted for publication Aug 23, 2007.

Address for reprints: Soren Schenk, MD, Cardiovascular Surgery, Heart Center NRW,

Georgstrasse 11, 32545 Bad Oeynhausen, Germany (E-mail: sschenk@arcor.de).

J Thorac Cardiovasc Surg 2008; 136:1076-7

$0022-5223 / \$ 34.00$

Copyright (c) 2008 by The American Association for Thoracic Surgery doi:10.1016/j.jtcvs.2007.08.084
}

This fourth-time major cardiac surgery to replace the aortic valve was uneventful, as was the subsequent postoperative course.

PATIENT 3. The third patient was a 24-year-old woman who had previously undergone 3 cardiac operations. A commissurotomy when she was 5 years old for aortic stenosis was followed by aortic valve replacements at 13 and 14 years of age, the latter for prosthesis dysfunction. A paravalvular leak diagnosed when the patient was 24 years old prompted interventional closure. Unfortunately, severe hemolysis developed immediately after the intervention. Fourth-time cardiac surgery for reoperative aortic valve replacement was performed 1 week later. As with our previous 2 patients, surgery in this challenging case and the subsequent postoperative course both went well.

\section{DISCUSSION}

Interventional closure of paravalvular leaks may evolve into an attractive treatment option for patients with multiple previous operations. Initial case reports have confirmed the feasibility of this approach for selected patients but have also revealed a variety of challenges. ${ }^{3}$ For instance, residual leaks were observed in 10 of 11 sites of device deployment in a series of 12 patients. ${ }^{4}$ Hemolysis may persist, even if the regurgitation is reduced (see patients 2 and 3 ). Thus the

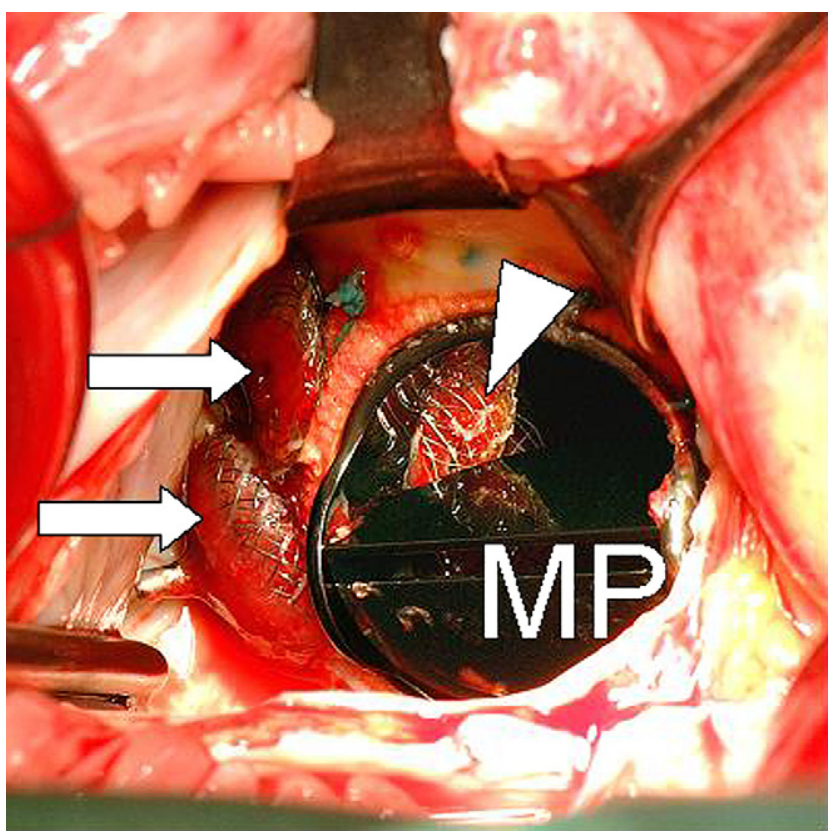

FIGURE 1. Intraoperative findings of obstructed leaflet of prosthetic valve in mitral position $(M P)$ in patient 1 . Two occluder devices are placed into paravalvular leak (arrows). One occluder protrudes into valve hinges and arrests leaflet (arrowhead). 


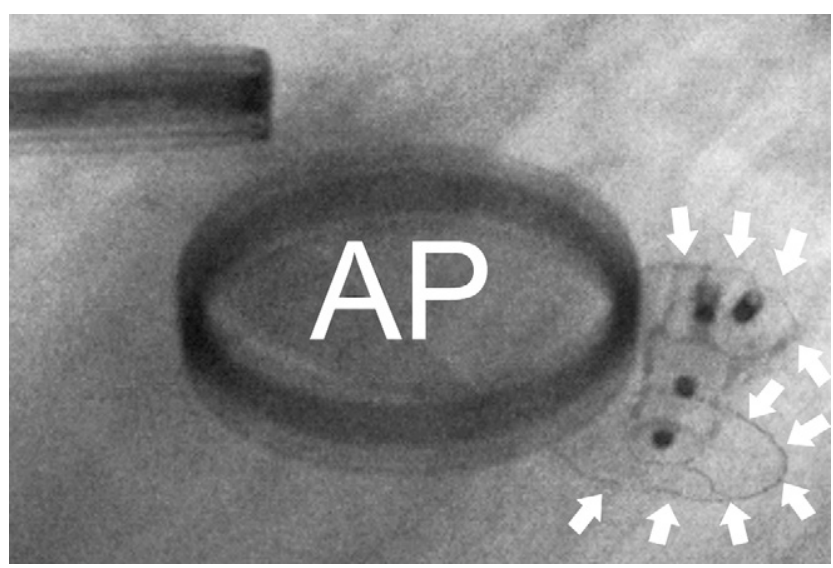

FIGURE 2. Interventional closure of paravalvular leak in patient 2. Two occluder devices are correctly placed (arrows). AP, Aortic prosthesis.

event-free survival (freedom from reoperation, reintervention, and significant residual shunt) was as low as $48 \%$ in a series of 24 patients. ${ }^{5}$ Common reasons for failure of this demanding intervention are poor imaging and unsuitable anatomy, such as crescent-shaped or multiple leaks and severe calcification. Additional limitations result from inadequate device configuration, because the occluders in use were originally designed for atrial and ventricular septal defects or patent ducts. Consequently, surgery still remains the criterion standard of treatment for paravalvular leaks while the technology of interventional closure is being advanced.

Our program comprised 1842 heart valve surgeries in 2006 , including 26 patients $(0.14 \%)$ operated on for para- valvular leaks. Even in this large series, the 3 cases presented here are unusual because of the multiple previous surgeries. These cases were technically challenging and of high risk, and avoiding fourth-time cardiac surgery for reoperative valve exchange by use of catheter-based intervention would have been preferable. We therefore advocate a multidisciplinary approach that includes interventional cardiologists and surgeons. Depending on level of hemolysis, severity of regurgitation, and anatomy of the paravalvular leak, the risk of surgery must be weighed against the likelihood of success of intervention. Both treatment options are clearly explained to the patient so that an informed decision can be made. Surgical backup in case of interventional complications is provided for every intervention as well. Future studies, perhaps with more suitable device technology, may address a hybrid approach, so that outcomes can be improved even for most complex cases of paravalvular leakage.

\section{References}

1. Akins CW. Results with mechanical cardiac valvular prostheses. Ann Thorac Surg. 1995;60:1836-44.

2. Akins CW, Bitondo JM, Hilgenberg AD, Vlahakes GJ, Madsen JC MacGillivray TE. Early and late results of the surgical correction of cardiac prosthetic paravalvular leaks. J Heart Valve Dis. 2005;14:792-800.

3. Pate GE, Al Zubaidi A, Chandavimol M, Thompson CR, Munt BI, Webb JG. Percutaneous closure of prosthetic paravalvular leaks: case series and review. Catheter Cardiovasc Interv. 2006;68:528-33.

4. Shapira Y, Hirsch R, Kornowski R, Hasdai D, Assali A, Vaturi M, et al. Percutaneous closure of perivalvular leaks with Amplatzer occluders: feasibility, safety, and shortterm results. J Heart Valve Dis. 2007;16:305-13.

5. Hein R, Skowasch M, Wunderlich N, Wilson N, Sievert H. Catheter treatment of paravalvular leaks using Amplatzer devices. Am J Cardiol. 2006;98(Suppl S): 231M.

\section{Resection of a giant thoracic solitary fibrous tumor through two separate thoracotomies}

Chao-Kai Hu, MD, ${ }^{\text {a }}$ Yih-Leong Chang, MD, ${ }^{\mathrm{b}}$ Wei-Cheng Lin, MD, ${ }^{\mathrm{a}}$ and Yung-Chie Lee, MD, PhD, ${ }^{\text {a Taipei, Taiwan }}$

Solitary fibrous tumor (SFT) of the pleura is an uncommon intrathoracic neoplasm. A middle-aged woman had progressive exertional dyspnea for 6 months, and eventually respiratory failure developed which necessitated ventilatory

\footnotetext{
From the Departments of Surgery ${ }^{\mathrm{a}}$ and Pathology, ${ }^{\mathrm{b}}$ National Taiwan University Hospital and National Taiwan University College of Medicine, Taipei, Taiwan.

Received for publication Oct 10, 2007; revisions received Dec 18, 2007; accepted for publication Dec 22, 2007.

Address for reprints: Yung-Chie Lee, MD, PhD, Department of Surgery, National Taiwan

University Hospital and National Taiwan University College of Medicine, No. 7,

Chung-Shan S Rd, Taipei, Taiwan 100 (E-mail: yclee@ntuh.gov.tw).

J Thorac Cardiovasc Surg 2008;136:1077-9

$0022-5223 / \$ 34.00$

Copyright (c) 2008 by The American Association for Thoracic Surgery

doi:10.1016/j.jtcvs.2007.12.015
}

support. After examination, a giant tumor was found to occupy the whole left pleural cavity with chest wall distention and severe mediastinal shift to the right side. We completely resected this giant tumor by two separate thoracotomies. The pathologic examination revealed an SFT weighing $5.1 \mathrm{~kg}$. Her respiratory condition improved markedly after the operation and she was discharged 23 days postoperatively.

\section{CLINICAL SUMMARY}

A 51-year-old woman, a nonsmoker, was referred to our hospital with endotracheal intubation and mechanical ventilation owing to respiratory distress caused by a huge lesion occupying the left chest cavity. A large tumor had been 